\title{
KNOWLEDGE, AWARENESS AND ATTITUDE REGARDING ERGONOMICS AMONG INTERNS AND POSTGRADUATE STUDENTS: A FOLLOW-UP STUDY
}

\author{
Mayank Kumar Parakh, Prof. Krishna Prasad D \\ Nitte (Deemed to be University), A B Shetty Memorial Institute of Dental Sciences (ABSMIDS), Department of Prosthodontics and \\ Crown \& Bridge, Mangalore, India
}

Correspondence: drkrishnaprasadd@nitte.edu.in

\begin{abstract}
OBJECTIVES:

To assess the knowledge attitude and awareness of interns and postgraduate students regarding ergonomic disorders and, to assess if they follow ergonomic postures following counselling regarding ergonomics among dental students in India
\end{abstract}

\section{METHODS:}

The questionnaire for this study was validated and, a Cronbach's alpha score of 0.84 was obtained. This study was conducted as a two-part study. In the first part, a questionnaire was given to the participants of the study. In the second part of the study, the subjects were observed on the 7th, 15th, and 30th day.

\section{RESULTS:}

Over half the participants i.e., 59.6\% (90 participants) preferred to perform the procedures while standing. This data on statistical analyses was found to be significant. ( $P$ value 0.041 ) In this study, $84.1 \%$ of participants had experienced symptoms in neck, shoulders, hands or back during working. (P value 0.039).

\section{CONCLUSION:}

Ergonomics is an important subject that must be taught to every medical professional.

\section{KEYWORDS}

Ergonomics, Ergonomic disorders, Occupation, Dentistry

\section{INTRODUCTION}

In our daily practice, dental specialists often work with incorrect postures owing to their working routines, habits and improperly designed workstation. [1] Ergonomics in the recent days has become a commonly used term as; almost

all the occupations are associated with some form of risk or occupational hazard. Ergonomics mainly deals with the modifying of the workplace to better fit the person working in it, rather than compromising and sustaining with the existing conditions. [2] 
Dentistry involves skilful preparation of the tooth with great degree of precision and control. In performing various dental treatments often, the muscles that are associated with the posture get strained and this leads to a lot of discomfort for the dental specialist. [2] If ergonomic postures are not followed by the dentist it leads to ergonomic disorders which are mostly musculoskeletal in nature. [3] Dental students both undergraduate and postgraduate students are at increased risk of various ergonomic disorders owing to the improper postural habits they follow during training at dental schools. [4]

There are various studies on ergonomics and related disorders in the literature, but these studies do not observe the dental students after they have been counselled about various ergonomic postures. Hence, this study was conducted as a two-part study. In the first part a questionnaire was given to the dental students in India which assessed their knowledge, awareness, and attitude regarding ergonomic disorders, following which, they were explained about the correct postures to be followed to avoid ergonomic disorders. In second part of the study the subjects were observed on the $7^{\text {th }}, 15^{\text {th }}$ and $30^{\text {th }}$ day to check if they followed correct ergonomic postures during dental procedures.

\section{MATERIAL AND METHODS}

\section{ETHICAL CLEARANCE:}

Ethical clearance was obtained from the institute's ethical committee board.

\section{SAMPLE SELECTION:}

A pilot study was conducted initially and following which the questionnaire of the study was validated. The questionnaire for this study was validated and, a Cronbach's alpha score of 0.84 was obtained. Using the data obtained from pilot study a sample size of 151 was calculated and used for the study. [ANNEXURE-1]

\section{METHODS:}

The study included 151 participants, 76 interns and 75 postgraduate students in India. The study was explained to the dental students and only after obtaining a written consent they were included in the study. Inclusion criteria for the study was subjects currently in their internship or are doing post-graduation studies, must be willing to give a written consent and they must not have a diagnosed musculoskeletal disorder. The participants were excluded if they were not willing to be observed and give a written consent. The participants were initially given a questionnaire to assess their knowledge, awareness and, attitude regarding ergonomic disorders. The questionnaire consisted of 15 questions assessing the aforementioned factors. Following this, they were given information regarding ergonomics and ergonomic positions for dental treatment.

In the second part of the study, over a period of one month, 3 observations were made on day 7,15 and 30 randomly during a dental procedure by 2 dentists trained in ergonomics and associated disorders. The participants ergonomic posture during dental procedures was noted. During the dental treatment it was noted if the subjects maintained a correctergonomic posture or not. [Figure -1] These observations were then tabulated and subjected to statistical analyses.

\section{STATISTICAL ANALYSES:}

Statistical analyses was done using SPSS software version 20.0

\section{RESULTS}

In this study a total of 151 dental students were included. The participants were asked 15 questions based on ergonomics. The 151 participants were divided into 4 groups based on age. (Table-1) This data when subjected to statistical analyses was found to be statistically significant. ( $P$ value 0.010) There were 40 males and 111 female participants in the study and this data on statistical analysis was significant. (P value 0.049) Right hand was the dominant hand in 94\% (142) of the subjects of the study.

The participants of the study were asked if they were aware of the term ergonomics and $92.1 \%$ (139) participants said that they were aware of the term and this data when subjected to statistical analyses was not significant statistically. When asked regarding if they followed ergonomics in their practices $53 \%$ said they followed it sometimes while $8.6 \%$ subjects said they never followed ergonomics in their practice. This data was statistically insignificant among the two groups. (P value 0.198)

Over half the participants i.e., $59.6 \%$ (90 participants) preferred to perform the procedures while standing. This data on statistical analyses was found to be significant. ( $P$ value 0.041 ) About $56.3 \%$ of the participants did not take any breaks during the procedure and this data was similar 
in both groups. (P value0.689) A little over three quarter of the participants said that they assumed an awkward position sometimes in both the groups and $7.9 \%$ and $12 \%$ individuals in postgraduate and intern groups respectively said that they never assume an awkward position. ( $P$ value 0.048) Most of the participants $88.1 \%$ said that their workplace was adequately lit and this data on statistical analyses was found to be statistically significant. ( $P$ value $0.041)$

About $56.6 \%$ (43 participants) of the postgraduates were aware of ergonomic stools as opposed to only $37.3 \%$ (28 participants) in the intern's category. ( $P$ value 0.018 ) The participants in both the groups were aware about posture related musculoskeletal disorders as $89.9 \%$ of the participants said they were aware of the disorders. (P value - 0.578) Furthermore, $84.1 \%$ of participants had experienced symptoms in neck, shoulders, hands or back during working. ( $P$ value 0.039). 99 participants were also aware of muscle strengthening exercises. ( $P$ value 0.777 ) Additionally, 32 participants in each group also performed muscle strengthening exercises. (Pvalue 0.944)

When the participants were asked if they had a medical consultation for their symptoms 30 postgraduates and 4 interns had a consultation for their musculoskeletal symptoms. (P value 0.028) However, when the participants were asked if they had undergone treatment for the symptoms only 19 participants had undergone treatment. (P value 0.208) All but 2 participants felt that ergonomics should be included in curriculum of dentistry. (P value 0.152) The participants were asked to report any conditions that predispose them to workplace injuries, 41 participants had a condition that predisposed them to such injuries. [ Figure2]

Following the questionnaire, the participants were informed of their ergonomics as they were observed on 3 instances on the $7^{\text {th }}, 15^{\text {th }}$ and on $30^{\text {th }}$ day. It was noted that 40 and 36 participants followed correct ergonomic posture on first assessment in postgraduates and interns respectively. ( $P$ value 0.370) There was a slight improvement in the second observation with 44 and 39 subjects following the correct posture among postgraduates and interns respectively. $(P$ value 0.572) On the third observation there was a significant decline among interns with only 20 following the ergonomic posture while 47 postgraduates followed the ergonomic postures on day 30. (P value 0.048)

\section{DISCUSSION}

The study compromised of 151 participants which were divided into two groups of 76 interns and 75 postgraduate students respectively. More than half the participants in our study did not take any breaks between patients, this is in accordance with the results obtained in Mumtaz et al [5] study where they found that $52.2 \%$ of interns did not take any breaks during procedures. Females had a higher incidence of musculoskeletal disorders when compared to male participants. This result is similar to the results obtained by Ovia et al, [6] Ayer et al,[7] and is contradicting the results of Gopinath et al. [8] This difference can be due to the fact that, more female participants were part of the study.

The present study noted that $59.6 \%$ (90 participants) preferred to perform the procedures while standing which is contradicting to study conducted by Hille et al, [9] In which the maximum participants preferred to use siting position for dental treatment. This difference can be attributed to the dental training at various institutes across India wherein, procedures such as impression making are thought while the dentist or the dental student stands. In our study $88.1 \%$ of participants thought that their workplace is adequately lit. In a study done by Martin et al, [10] it was noted that adequate lighting can reduce the incidence of ergonomic disorders.

Furthermore, $84 \%$ of participants reported that they had some form of disturbance in their neck, back, shoulder or hand while performing procedures. This data is similar to results that were noted in Parkali and Jowkar's [11] study where $73 \%$ of the participants reported symptoms due to work related disorders. In the present study postgraduate students showed more acceptance of following ergonomic postures than interns. This is in accordance to the study conducted by Kalghatgi et al [12], who showed that postgraduates had better acceptance than interns regarding ergonomics. This can be attributed to the fact that over the undergraduate years, the postgraduates might have experienced musculoskeletal pain associated with posture or might have observed the same with their colleagues.

In this study all but 2 participants were of the opinion that ergonomics should be included in the curriculum of dental students. This is in accordance with a study conducted by Rajeshwari et al, [13] where $83 \%$ of the postgraduate 
students and $90 \%$ of the interns shared the same opinion as the results of our study. This is probably due to fact that a significant number of dentist's in their lifetime experience musculoskeletal disorders or pain associated with their work. If ergonomics is taught and reinforced in the curriculum the incidence of such disorders might reduce significantly.

The dental curriculum currently does not include ergonomics and its related disorders and hence it is of utmost importance that this be incorporated into the curriculum so as to reduce the incidence and increase the awareness regarding ergonomic disorders. The authors of the paper strongly recommend the inculcation of ergonomics into the dental curriculum. The limitation of the study is that a longer follow-up of the participants would have given a better idea on long term acceptance and adherence of reinforcing ergonomics and related disorders.

\section{CONCLUSION}

Ergonomics is an important subject that must be taught to every medical professional. The present study showed that the knowledge, awareness and attitude can be improved to a great extent among both interns and postgraduate students of ergonomics were to be incorporated into the curriculum.

\section{ACKNOWLEDGEMENT:}

Our acknowledgement extends to A B Shetty Memorial Institute of Dental Sciences, NITTE (Deemed to be University).

\section{ETHICAL APPROVAL:}

Was obtained from institutes ethical clearance committee

\section{CONSENT TO PARTICIPATE:}

A written consent was obtained from participants before beginning the study

\section{References}

1. Kalghatgi S, Prasad KV, Chhabra KG, Deolia S, Chhabra C. Insights into ergonomics among dental professionals of a dental institute and private practitioners in Hubli-Dharwad twin cities, India. Saf Health Work 2014; 5:181-5
2. Sachdeva A, Bhateja S, Arora G. Ergonomics in dentistry: A comprehensive review. J Dent Res Rev 2020;7:32-5

3. Gupta S. Ergonomic applications to dental practice. Indian J Dent Res 201 1;22:816-22

4. Horton SJ, Johnstone CL, Hutchinson CM, Taylor PA, Wade KJ. Clinical working postures of bachelor of oral health students. N Z Dent J 201 1;107:74-8

5. Mumtaz R, Haroons, Sajjad S, Masoud S, Hashmi J.Ergonomics knowledge and practices of dental interns in islamabad, Pak Oral Dent J.38: 341-44

6. Oviyavj, Thenmozhi M. Awareness on the effects of ergonomics interventions on work-related upper extremity musculoskeletal disorders among undergraduate dental students. Drug Intervention Today.2018;10:2531-35

7. Ayers KM, Thomson WM, Newton JT, Morgaine KC, Rich AM. Self-reported occupational health of general dental practitioners. Occup Med (Lond) 2009;59:1 42-8

8. HillGe, Seget A, Pytko-Polończyk J. Ergonomics in the professional work of the dentist - a questionnaire survey. Dental Forum.2013;2: 45-52

9. 9 Gopinadh A, Devi KN, Chiramana S, Manne P, Sampath A, Babu MS, et al. Ergonomics and musculoskeletal disorder: As an occupational hazard in dentistry. J Contemp Dent Pract 2013;1 4:299-303.

10. Martin M, Ahearn D, Gotcher J, Smith S, Verhagen C, Ismail $A$, et al. An Introduction to Ergonomics: Risk Factors, MSDs, Approaches and Interventions - A Report of the Ergonomics and Disability Support Advisory Committee (EDSAC) to Council on Dental Practice (CDP). Chicago: American Dental Association; 2004. Available from:vailable from: http://www.rapdental.com/pdfs/topics ergono mics paper (2).pdf. [Last accessed 2013 Nov 27]. [Last accessed 2021 Jan 09].

11. Pargali N, Jowkar N. Prevalence of musculoskeletal pain among dentists in Shiraz, Southern Iran. Int J Occup Environ Med 2010;1:69e74.

12. Kalghatgi S, Prasad KVV, Chhabra GK, Deolia S, Chhabra C Insights into Ergonomics Among Dental Professionals of a Dental Institute and Private Practitioners in HublieDharwad Twin Cities, India. Saf Health Work 2014;5:181e185

13. Rajeshwari SR, Gowda TM, Kumar TA, Arya K, Mehta DS. Assessment of interns and postgraduate dental student's knowledge regarding equipment ergonomics. Indian J Dent Res. 2016;27:256-61 


\section{APPENDIX}

TABLE -1: AGE DISTRIBUTION OF PARTICIPANTS OF THE STUDY

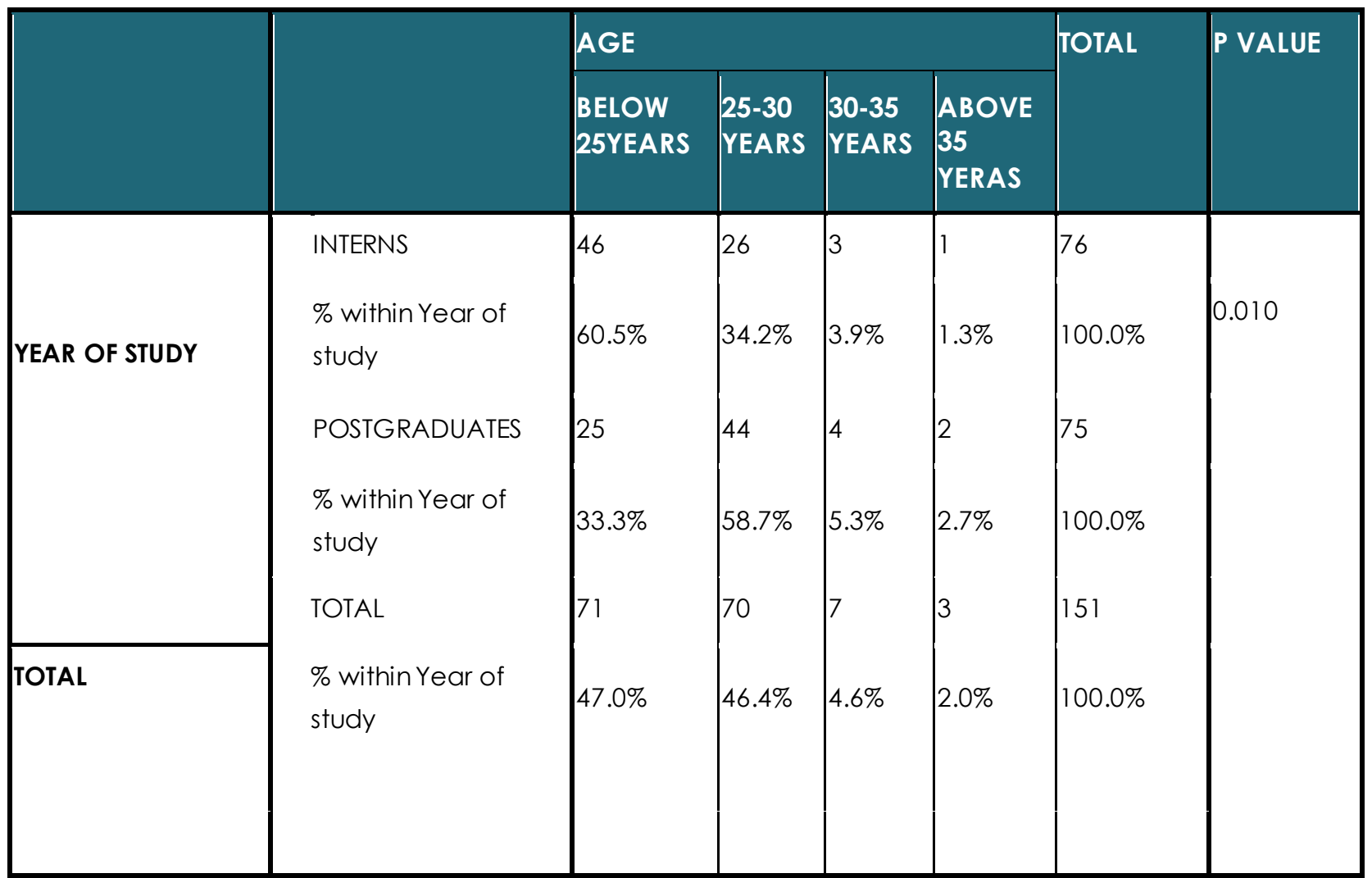

FIGURE - 1 STUDY DESIGN

WRITTEN CONSENT

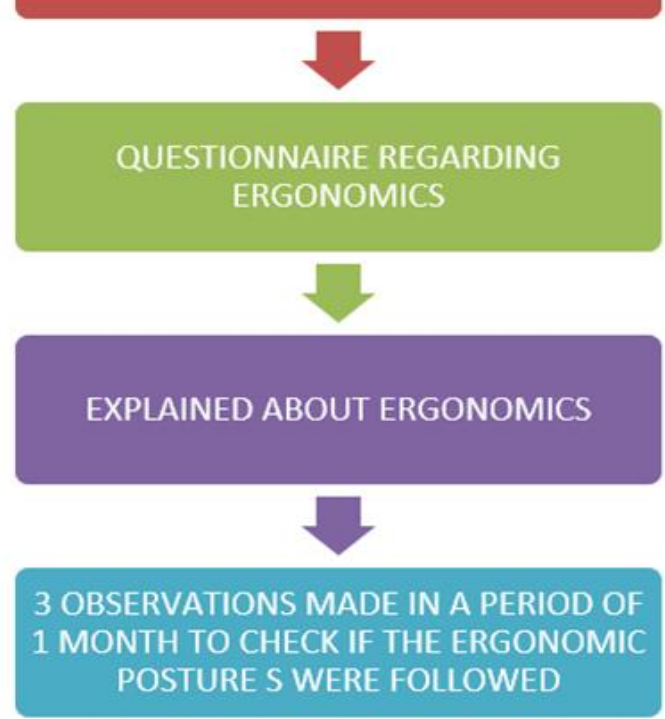


FIGURE -2 PARTICIPANTS WITH DISORDERS PREDISPOSING THEM TO WORKPLACE INJURIES

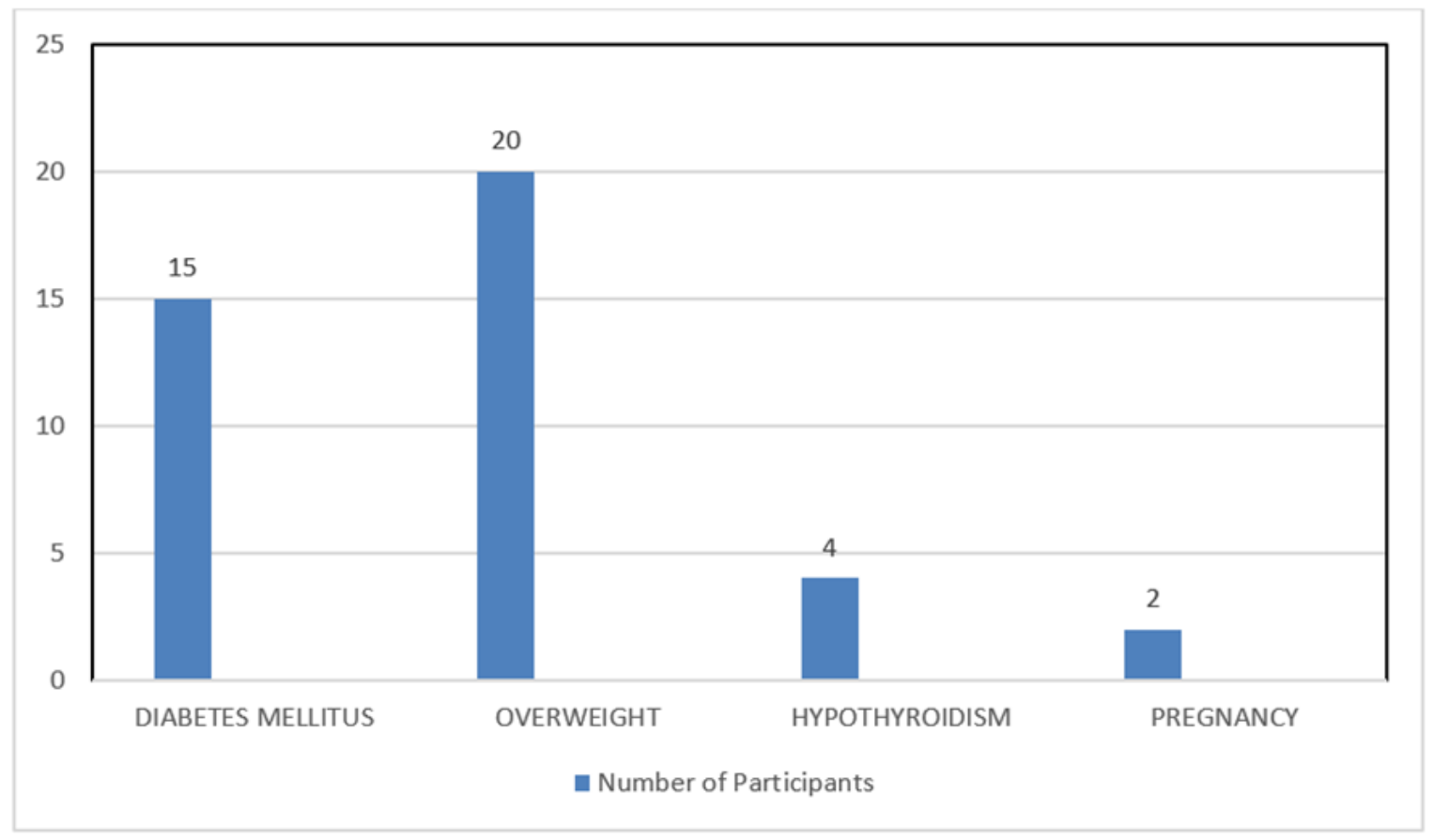

